\title{
Feasibility study of iron mineral separation from red mud by high gradient superconducting magnetic separation
}

\author{
Yiran Li, Jun Wang*, Xiaojun Wang, Baoqiang Wang, Zhaokun Luan

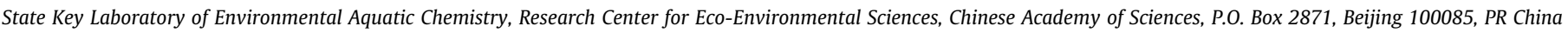

\section{A R T I C L E I N F O}

\section{Article history:}

Received 4 June 2010

Received in revised form 29 November 2010

Accepted 5 December 2010

Available online 13 December 2010

\section{Keywords:}

Red mud

Iron separation

High gradient

Superconducting magnet

\begin{abstract}
A B S T R A C T
The disposal of bayer red mud tailings now seriously threats the environment safety. Reduction and recycling of red mud is now an urgent work in aluminum industry. High gradient superconducting magnetic separation (HGSMS) system was applied to separate the extreme fine RM particles $(<100 \mu \mathrm{m})$ into high iron content part and low iron content part. Two sorts of RM were fed in the HGSMS. The iron oxide contents in concentrates were about $65 \%$ and $45 \%$ when RM 1 \# and RM 2 \# were fed respectively. Meanwhile, the residues contained $52.0 \%$ or $14.1 \%$ iron oxide in residues after eight separation stages when RM $1 \#$ and RM $2 \#$ were fed respectively. The mass recovery of iron concentrates was about $10 \%$ after once separation process regardless of RM 1\# or RM $2 \#$ was fed. Extreme fine particles $(<10 \mu \mathrm{m})$ could be captured in the HGSMS. Intergrowth of $\mathrm{Fe}$ and other elements is disadvantages for iron mineral separation from RM by HGSMS. Some improvement should be studied to enhance the efficiency of iron separation. It is possible for HGSMS to separate RM into high iron content part and low iron content part, the former part could be used in iron-making furnace and the later part could be recycling to sintering process for alumina production or used as construction material.
\end{abstract}

(c) 2010 Elsevier B.V. All rights reserved.

\section{Introduction}

Red mud (RM) is a by-product after the caustic digestion of bauxite ores during the production of alumina. About 1-2 tons of RM residues (dry weight) are generated for a ton of alumina produced. At present, over 90 millions tons of caustic RM must be disposed of annually all around the world [1]. RM is a highly alkaline waste material with $\mathrm{pH} 10-12.5$ and mainly composed of fine particles consist of aluminum, iron, silicon, calcium, titanium oxides and hydroxides. Such residue has accumulated over years and causes a serious environmental problem due to its high alkalinity and large amount. Currently, most RM generated from alumina plants is disposed in landfills or dumped at sea. The disposal and management of RM tailing residues constitute one of the most challenging problems facing the bauxite and alumina industry.

Up to now, in order to reduce the amount of RM, more and more researches had focused on the application of such residue tailings. RM has found limited applications in building materials [2], pigments and paints [3], metal recovery [4], catalysis, ceramic production [5], soil amendment [6], water or gas treatment [7], etc.

However, application of iron concentrated red mud with fine particles was limited. Take Shandong Branch, Aluminum

\footnotetext{
* Corresponding author. Tel.: +86 10 62849150; fax: +86 1062849198 .

E-mail addresses: lyr2006xd@yahoo.com.cn (Y. Li), junwang@rcees.ac.cn (J. Wang).
}

Corporation of China for example, $\mathrm{Fe}_{2} \mathrm{O}_{3}$ consists from 30 to $60 \%$ in bayer red mud tailings with the particles size less than $100 \mu \mathrm{m}$. This sort of RM was disposed in landfills annually. Iron minerals separation from red mud with considered costs is significant for reducing red mud disposal [8]. High iron content RM could be used in iron-making furnace while the low iron content RM could be recycling in sintering process for aluminum production or used as building materials.

The main mineral phase of iron in bayer red mud tailings could be hematite, goethite or magnetite, etc. [8], which were magnetic or weak magnetic materials. Therefore, magnetic separation could be an attractive method to recover the iron minerals. Magnetic separation is a method for the separation of particles on the basis of their magnetic properties. Magnetic separation was found effective in recycling, purification [9] and other areas. The iron minerals can be efficiently separated by magnetic separation even if the precipitate is very fine. This is because the strong magnetic force $\left(F_{m}\right)$ acts on magnetic particles when they move through a magnetic intensity $(H)$ [10], the magnetic force $\left(F_{m}\right)$ could be expressed as follows:

$F_{m}=V \cdot M(H) \cdot d H / d x$

where $V$ is the volume of the magnetic particle, $M(H)$ is the magnetization of the magnetic particle in a magnetic intensity $(H)$ and $d H$ / $d x$ is the magnetic gradients. 
When the magnetization of the particle gets saturated, $F_{m}$ is shown in equation [11]:

$F_{m} \cong \frac{4}{3} \pi b^{3} M(H) d H / d x$

where $b$ is the radius of the dispersed particle. Consequently, magnetic particles are captured on a filter matrix by the magnetic tractive force $\left(F_{m}\right)$ that overcomes other competing forces of gravitation, hydrodynamics and inertia, etc. The drag force $\left(F_{D}\right)$ to the particle from the fluid is shown by:

$F_{D}=6 \pi \mu b\left(v_{f}-v_{p}\right)$

where $\mu, b, v_{f}$ and $v_{p}$ are the fluid viscosity, radius of the spherical particle, fluid velocity and particle velocity, respectively.

Therefore, strong magnetic intensity $(H)$ and high magnetic gradients $(d H / d x)$ was needed for fine magnetic particles separation from the matrix. Traditional magnetic separation process was hard to separate the iron particles less than $100 \mu \mathrm{m}$ [12]. Considering the extreme fine particles of RM, advanced magnetic separation method should be considered. In order to increase the magnetic properties of RM particles, Roasting methods followed by magnetic separation was studied by Liu et al. [8] for iron mineral separation from RM. However, roasting process was a high cost procedure which can hardly be used in industrial scale.

Superconducting magnets have a number of advantages over resistive electromagnets in fine magnetic materials recovery [13]. They can achieve an order of magnitude stronger field than ordinary ferromagnetic-core electromagnets, which can be more efficient in separating fine magnetic particles. Nowadays, the cost for superconducting magnets is considerable for industrial application because of the breakthrough of refrigeration system.

High gradient superconducting magnetic separation (HGSMS) process is now becoming a promising separation method for weakly magnetic minerals with fine particles. HGSMS had been used in kaolin refinement [14]. Radioactive water reducing and iron impurity removal from high-temperature boiler liquids in electrical power plants. However, the attempt of reducing RM tailings using HGSMS was never reported. Therefore, the main object of this work are (1) design a superconducting magnetic separation system, (2) attempt to separate iron minerals from RM and (3) discussing the improvement of using HGSMS in iron minerals recovery from RM.

\section{Materials and methods}

\subsection{Red mud tailings}

Iron content of RM has great discrepancy due to the bauxite used in bayer process. For example, there are two main types of RM (iron content about $30 \%$ or $60 \%$ ) generated in Shandong Branch, Aluminum Corporation of China although the bauxites used in bayer process were both imported from Indonesia. These two types of RM tailings were both collected after the cyclone reactors. Meanwhile, the chemical compositions of the two types of RM tailings were shown in Table 1.

An X-ray diffractometer (ShimadzuXRD-6000) operated at $40 \mathrm{kV}$ and $30 \mathrm{~mA}$ was used to identify the crystal structure and crystallinity with $\mathrm{Cu} \mathrm{K \alpha}(l=0.15418 \mathrm{~nm})$ radiation over the range

Table 1

Chemical composition of RM 1\# and RM 2\#.

\begin{tabular}{lrrrrrrrl}
\hline$\%$ & $\mathrm{SiO}_{2}$ & $\mathrm{Fe}_{2} \mathrm{O}_{3}$ & $\mathrm{Al}_{2} \mathrm{O}_{3}$ & $\mathrm{CaO}$ & $\mathrm{TiO}_{2}$ & $\mathrm{Na}_{2} \mathrm{O}$ & $\mathrm{K}_{2} \mathrm{O}$ & Ignition loss \\
\hline RM 1\# & 6.42 & 58.74 & 13.01 & 0.98 & 4.40 & 3.78 & 0.05 & 11.63 \\
RM 2\# & 21.24 & 29.79 & 22.96 & 2.03 & 1.83 & 8.93 & 0.03 & 12.19 \\
\hline
\end{tabular}

of 2 from $10^{\circ}$ to $80^{\circ}$. The mineral phase of these two types RM shows little discrepancy, hematite, alumogoethite, anatase, quartz, sodium-silicon residue, $\mathrm{CaCO}_{3}, \alpha-\mathrm{Al}(\mathrm{OH})_{3}$ were all detected. Meanwhile, the mineral phase of RM used in this work shows little discrepancy with other studies [15].

\subsection{Superconducting magnetic separation systems}

Magnetic separation process was carried out in a superconducting magnet (Institute of Electrical Engineering, Chinese Academy of Sciences, China). The HGSMS system was shown in Fig. 1 and a schematic diagram of this system is illustrated in Fig. 2. Approximate $1000 \mathrm{~g}$ carbon steel wool with a diameter of $50 \mu \mathrm{m}$ was filled in a stainless steel column ( $100 \mathrm{~cm}$ height, $15 \mathrm{~cm}$ diameter).

\subsection{Process of iron minerals recovery}

Fig. 2 shows the continuous superconducting magnetic separation process that uses the concept of a reciprocating matrix. After a certain magnetic intensity was maintained, $1500 \mathrm{~g}$ RM (dry weight) were homogeneous dispersed in $25 \mathrm{~L}$ water which were pumped into the magnetic field (full with steal wool) by a submersible pump ( $2 \mathrm{~T} /$ $h$ ). The outflow from the steal wool matrix was recycled to the red mud tailing pool. After 5 min circulated-flow, the steal wool matrix was placed out of the magnetic field by a braking device. At the mean time, iron concentrated RM (concentrates) were washed out and collected by washing water using a water pump $(12 \mathrm{~T} / \mathrm{h})$. The quality and iron content of concentrates, residues and steal wool retention RM were measured.

\subsection{Methods of analysis}

Iron content in red mud was measured by Inductively Coupled Plasma Atomic Emission Spectroscopy (ICP-AES, Prodigy) after the solid phase was digested by microwave oven procedure (MARS, CEM). The digestion solution was Aqua regia $\left(3+1 \mathrm{HCl}-\mathrm{HNO}_{3}\right)$. Size distributions were determined using a Malvern Mastersizer 2000 (Malvern Co., United Kingdom) with a ultrasonic deconcentrator, which ascertains size by analysis of forward scattered light. The micrograph and microanalysis of the samples were determined using a $30 \mathrm{kV}$ HITACHI S-3000N scanning electron microscope (SEM).

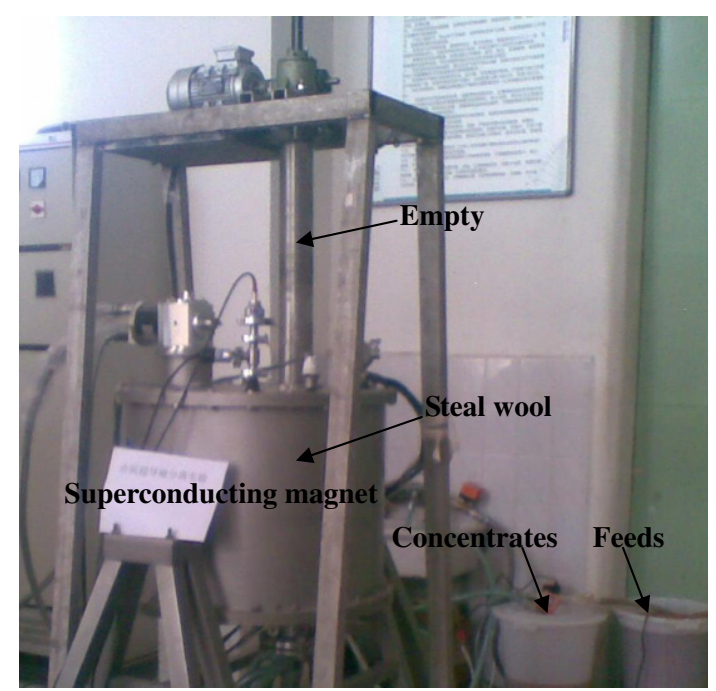

Fig. 1. Photograph of the high gradient superconducting magnetic separation system. 


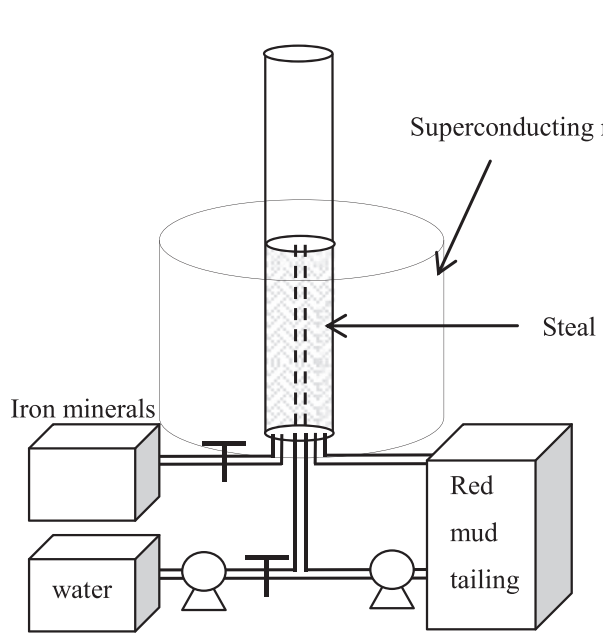

(a)

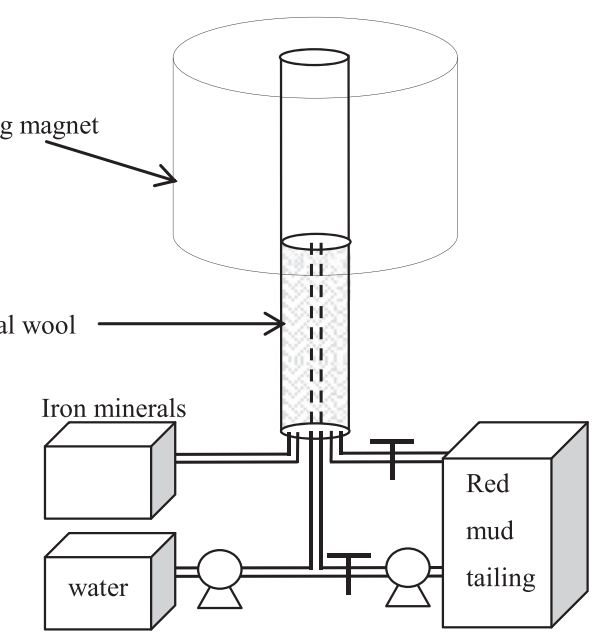

(b)

Fig. 2. Schematic explanation of HGSMS equipment, (a) RM feed process and (b) concentrates collected process.

\section{Results and discussion}

\subsection{Effects of magnetic intensity on iron separation from RM}

Magnetic intensity is a fundamental factor in the magnetic separation procedure. Effects of magnetic intensity on iron oxide separation from RM 1\# or RM 2\# were shown in Fig. 3a and b, respectively. Two sorts of RM (RM 1\# and RM 2\#) were dispersed in water and fed to the high gradient superconducting magnetic separator. After one stage separation described in Section 2.3, concentrates and residues were collected. The qualities and iron contents of concentrates and residues were measured.

It is shown in Fig. 3a and b, Iron contents slightly decreased when magnetic intensity improves from $2 \mathrm{~T}$ to $4 \mathrm{~T}$. Meanwhile, the qualities of concentrates when RM 1\# and 2\# fed were increased from $10.0 \%$ to $14.2 \%$ and $7.4 \%$ to $11.1 \%$, respectively. Meanwhile, after the first stage separation, iron contents in residues were slightly lower compared high magnetic intensity to low one. The reasons may be that magnetic tractive force $\left(F_{m}\right)$ increased in high magnetic intensity. RM with little iron content could be trapped in some weakly magnetic adsorption sites, thus leads to lower iron content in concentrates. At the meantime, more effective magnetic adsorption sites of steal wool slightly reduced the iron content in residues.

Iron content in concentrates was significantly higher than RM 1\# feeds (about 55\% improved), however, the iron content was only slightly increased when RM $2 \#$ was fed (about $10 \%$ improved). The efficiency of HGSMS on low iron content RM (2\#) is higher than high iron content RM (1\#). The mineral phase and particle size of these two sorts of RM shows little difference, the discrepancy of magnetic separation efficiency between RM 1\# and RM 2\# may because of the iron content in RM feeds.

\subsection{Effects of magnetic separation stages on iron separation from RM}

The mass balance of RM 1\# and RM 2\# were shown in Table 2. An amount of $1500 \mathrm{~g}$ RM was fed in the HGSMS, after the first separation stage, $170.3 \mathrm{~g}$ and $130.2 \mathrm{~g}$ concentrates was collected when RM 1\# and RM 2\# were fed respectively. The residues were then fed in the HGSMS for the second separation stage. Concentrates were collected and the residues were ready for the next separation stage. Concentrates, residues and steal wool retentions were collected and the weight was calculated (Table 2). The mass recovery of this experiment was about 95\% regardless which kinds of RM
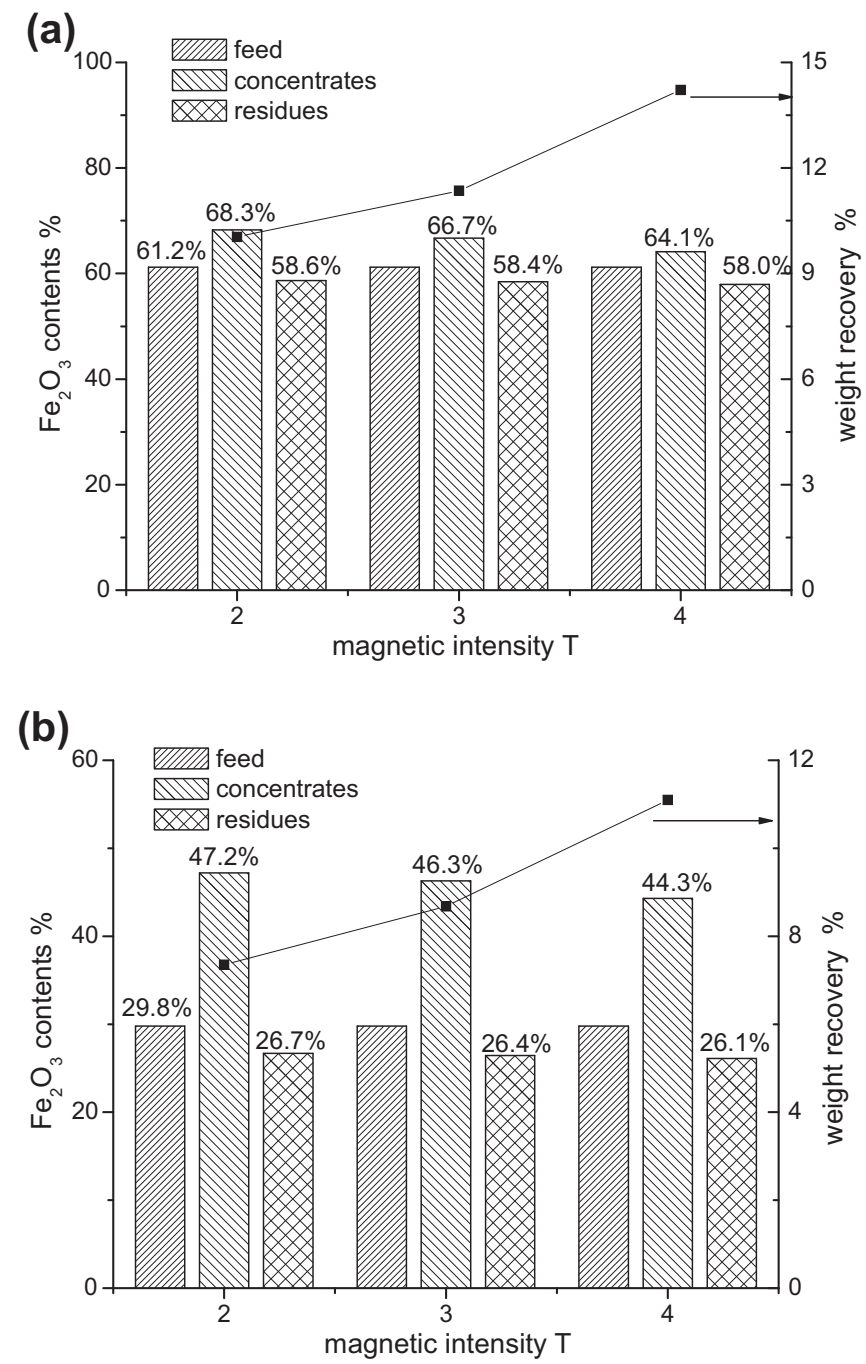

Fig. 3. Effects of magnetic intensity on iron mineral separation from RM, (a) RM 1\# and (b) RM 2\#.

was fed. It is shown that one part of RM (about 10\%) was entrapped in steal wool which cannot be rushed out by backwashing water 
Table 2

Quality of concentrates (collected in each separation stages), residues (after the continuous separation process) and steal wool retention (after the separation process).

\begin{tabular}{|c|c|c|c|c|c|c|c|c|c|c|c|c|}
\hline & Feed & $1 \#$ & $2 \#$ & $3 \#$ & $4 \#$ & $5 \#$ & $6 \#$ & 7\# & $8 \#$ & Residues & Steal wool retention & Recovery (\%) \\
\hline Quality (g) RM 1\# & 1500 & 170.3 & 140.8 & 125.7 & 111.4 & 108.5 & 96.7 & 88.6 & 73.1 & 415.1 & 147.1 & 94.8 \\
\hline Quality (g) RM 2\# & 1500 & 130.2 & 115.8 & 103.2 & 93.3 & 81.2 & 76.6 & 59.6 & 39.1 & 625.6 & 145.0 & 95.3 \\
\hline
\end{tabular}

(a)

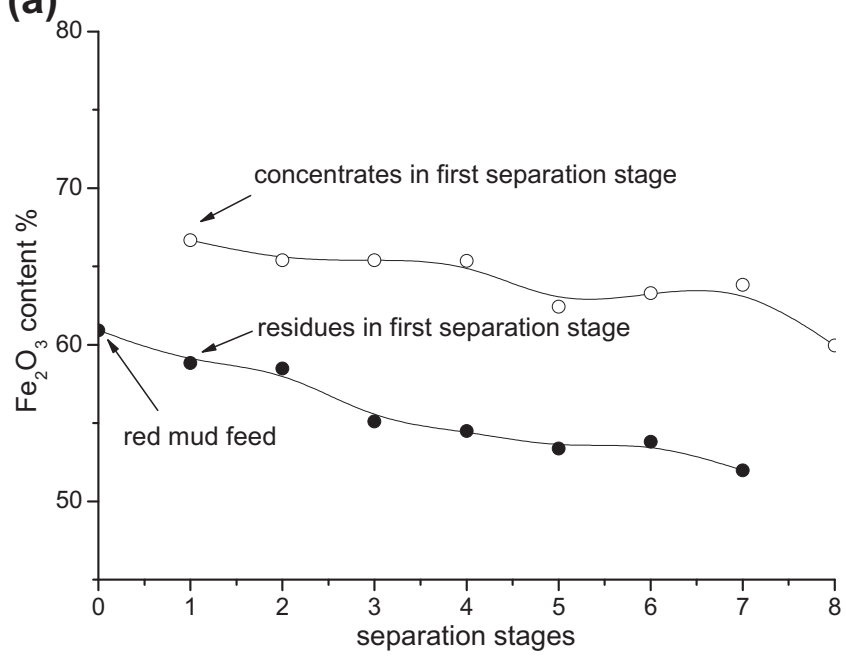

(b)

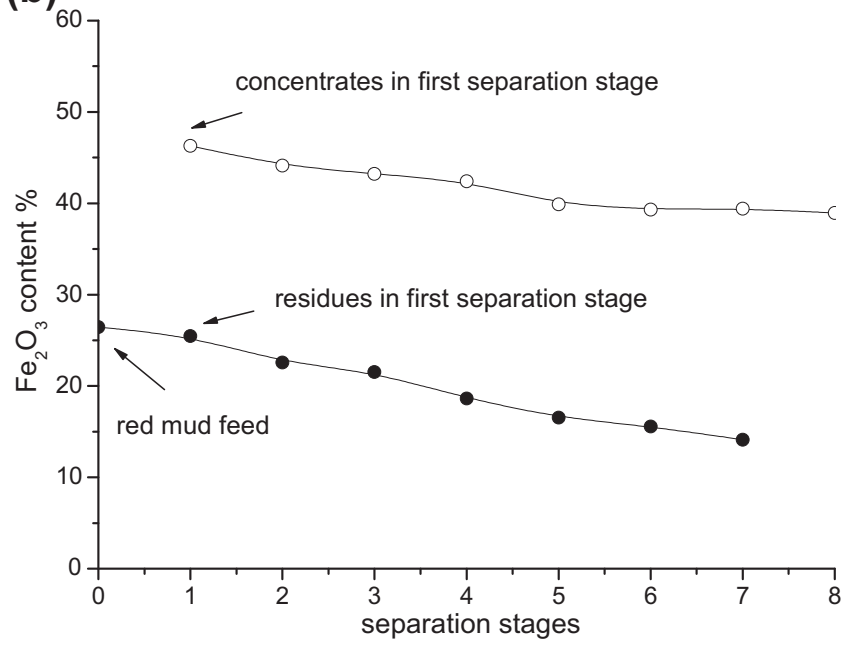

Fig. 4. Iron contents in concentrates and residues in different separation stages, (a) RM $1 \#$ and (b) RM 2\#.

after the eight separation stages. The steal wool entrapped RM will surely lead to the experimental uncertainties. The improvement should consider the uniform pores of filling materials which could reduce the physical interception.
The variation of iron contents in concentrates and residues after different separation stages were shown in Fig. 4a (RM 1\#) and b (RM 2\#). Iron contents in concentrates were not a constant value but gradually decreased during the magnetic separation process. Iron oxide content of concentrates was about 66.7-60\% and 46.3-39.0\% when RM 1\# and RM 2\# were fed, respectively. Meanwhile, after the eight separation stages, iron oxide content in residues were $52.0 \%$ and $14.1 \%$ when RM $1 \#$ and RM 2\# were fed, respectively. The phenomena that magnetic separation efficiency was affected by iron contents in RM feeds which is accordance to Section 3.1.

The chemical composition and weight recovery of HGSMS were shown in Tables 3 and 4 when the magnetic intensity was 3 T. RM $1 \#$ or $2 \#$ was fed in the HGSMS, the concentrates (1) and residues (1) were collected after the first separation stage. Concentrates (2) and residues (2) were collected in the second separation stage when residues (1) were fed in the HGSMS system. After that, concentrates (3) and residues (3) were collected when concentrates (1) were fed.

Iron oxide contents in concentrates (2) were much higher than concentrates (1) regardless which kind of RM was fed. Iron oxide content in concentrates (3) of RM $1 \#$ was about $73.2 \%$, which could be used in blast furnace. Considering the ignition loss (11-12\%) of concentrates, the iron oxide content in concentrates (1) of RM 2\# could reach higher than $60 \%$.

\subsection{Particle size distribution}

In order to investigate the effect of RM particle size on the separation of iron in the high gradient superconducting magnetic separator, the particles size of RM feed, residues after eight separation stages and concentrates were measured. The particle size when RM 1\# or RM 2\# was fed shows little discrepancy and the particle size distribution of RM 2\# was shown in Fig. 5. It is shown that concentrates of RM 2\# contained extremely fine particles $(<10 \mu \mathrm{m})$. The limitation of magnetic separation in extremely fine particles was not observed when utilizing HGSMS for iron separation from RM. There may be three reasons for the phenomena, (1) the magnetic force $\left(F_{m}\right)$ was sufficient for fine particles captured, (2) fine particles aggregated in the magnetic intensity due to the magnetic agglomeration process and (3) fine particles aggregated due to the brownian motion process.

Particles with large size (larger than $100 \mu \mathrm{m}$ ) were not detected in concentrates of RM. The amount of large particles in concentrates was more than original RM. This result indicates the disadvantages of this experimental system. A perfect iron mineral

Table 3

Weight recovery and iron contents of concentrates and residues (RM 1\#).

\begin{tabular}{|c|c|c|c|c|c|c|c|c|c|}
\hline & \multirow[t]{2}{*}{ Weight (g) } & \multirow{2}{*}{$\begin{array}{l}\text { Weight } \\
\text { recovery (\%) }\end{array}$} & \multicolumn{7}{|c|}{ Chemical composition (\%) } \\
\hline & & & $\mathrm{Fe}_{2} \mathrm{O}_{3}$ & $\mathrm{SiO}_{2}$ & $\mathrm{Al}_{2} \mathrm{O}_{3}$ & $\mathrm{CaO}$ & $\mathrm{TiO}_{2}$ & $\mathrm{Na}_{2} \mathrm{O}$ & Ignition loss \\
\hline Red mud feed & 1500.0 & 100.0 & 61.2 & 6.2 & 14.8 & 0.4 & 2.1 & 2.9 & 12.2 \\
\hline Concentrates (1) & 170.26 & 10.8 & 66.7 & 7.9 & 12.8 & 2.1 & 2.0 & 2.2 & 11.7 \\
\hline Residues (1) & 1329.7 & & 60.9 & 6.5 & 15.0 & 2.5 & 1.8 & 2.9 & 12.3 \\
\hline Concentrates (2) (residues ( 1 ) feed) & 140.82 & 7.4 & 65.4 & 6.2 & 12.4 & 2.0 & 2.7 & 1.9 & 11.7 \\
\hline Residues (2) (residues (1) feed) & 1189.0 & & 58.8 & 6.6 & 15.8 & 2.3 & 1.3 & 2.9 & 12.8 \\
\hline Concentrates (3) (concentrates (1) feed) & 97.7 & 6.6 & 73.2 & 5.8 & 11.0 & 2.1 & 1.6 & 1.4 & 11.6 \\
\hline Residues (3) (concentrates (1) feed) & 72.6 & & 58.3 & 8.4 & 15.0 & 2.7 & 2.6 & 2.5 & 12.6 \\
\hline
\end{tabular}


Table 4

Weight recovery and iron contents of concentrates and residues (RM 2\#).

\begin{tabular}{|c|c|c|c|c|c|c|c|c|c|}
\hline & \multirow[t]{2}{*}{ Weight (g) } & \multirow{2}{*}{$\begin{array}{l}\text { Weight } \\
\text { recovery (\%) }\end{array}$} & \multicolumn{7}{|c|}{ Chemical composition (\%) } \\
\hline & & & $\mathrm{Fe}_{2} \mathrm{O}_{3}$ & $\mathrm{SiO}_{2}$ & $\mathrm{Al}_{2} \mathrm{O}_{3}$ & $\mathrm{CaO}$ & $\mathrm{TiO}_{2}$ & $\mathrm{Na}_{2} \mathrm{O}$ & Ignition loss \\
\hline Red mud feed & 1500.0 & 100.0 & 29.4 & 26.4 & 20.5 & 1.7 & 1.6 & 7.9 & 11.9 \\
\hline Concentrates (1) & 130.2 & 8.7 & 46.3 & 15.4 & 25.2 & 1.3 & 2.0 & 4.8 & 15.4 \\
\hline Residues (1) & 1147.1 & & 26.4 & 20.5 & 24.2 & 2.1 & 2.0 & 8.6 & 13.6 \\
\hline Concentrates (2) (residues (1) feed) & 115.8 & 7.7 & 44.1 & 15.9 & 19.0 & 1.8 & 2.2 & 6.6 & 11.7 \\
\hline Residues (2) (residues (1) feed) & 1007.7 & & 21.6 & 25.1 & 25.6 & 2.4 & 1.8 & 9.6 & 12.8 \\
\hline Concentrates ( 3 ) (concentrates ( 1 ) feed) & 79.3 & 5.3 & 51.7 & 12.3 & 15.8 & 1.6 & 2.4 & 4.8 & 11.5 \\
\hline Residues (3) (concentrates (1) feed) & 73.6 & & 26.1 & 19.8 & 24.7 & 2.6 & 2.0 & 8.7 & 14.0 \\
\hline
\end{tabular}

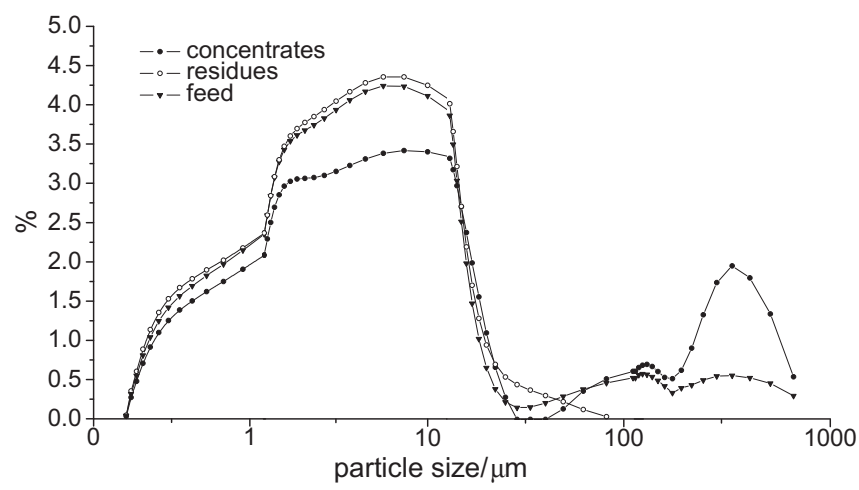

Fig. 5. Particle size distribution of concentrates, residues and red mud feed (RM 2\#).

separator should only differentiate the high iron content part with the low iron content part. Other factor like particle size should not show an obvious difference. The reasons for the capture of large particles may because of the small interspace in the steal wool fillings.

\subsection{SEM and element distribution}

The morphology and surface elements distribution of RM 2\# was studied by a SEM combined to an EDAX KEVEX level 4 . The EDAX and dot maps of iron showed that iron distributed on the surface of RM 2\#. Silicon, aluminum and sodium were the major elements association with iron (Fig. 6 and Table 5).

According to this study, RM cannot be separated into high iron content part and non iron content part when simple magnetic
Table 5

Elemental content on the surface of RM.

\begin{tabular}{ll}
\hline Element & Weight (\%) \\
\hline OK & 36.81 \\
NaK & 05.39 \\
AlK & 07.49 \\
SiK & 11.58 \\
TiK & 01.67 \\
FeK & 25.16 \\
\hline
\end{tabular}

separation used. Meanwhile, the mineral phase of both RM 1\# and RM 2\# shows little changes before and after the HGSMS process. Intergrowth of $\mathrm{Al}, \mathrm{Si}, \mathrm{Na}, \mathrm{Ti}$ and $\mathrm{Fe}$ was evident in the dot maps of elements shown in Fig. 7. The intergrowth property of RM was disadvantage for iron mineral separation by HGSMS. However, results of the HGSMS showed that RM 2\# could be separated into relatively high iron content part and low content part. Although the intergrowth of different elements was evident, the uneven distribution was expected. In this way, HGSMS could be a potential method for iron separation from RM.

\subsection{Possible improvement on the HGSMS for iron separation from RM}

The separation process is attractive if RM could be separated into high iron content part and low iron content part. RM with high iron content could be the source for iron-making furnace while RM with low iron content could reuse in sintering process for alumina production.

Extreme fine particles were captured in the separation process by the experimental HGSMS system. Therefore, it is possible for utilizing HGSMS in iron mineral separation from extreme fine particles, just like RM. However, there are lots of disadvantages in this
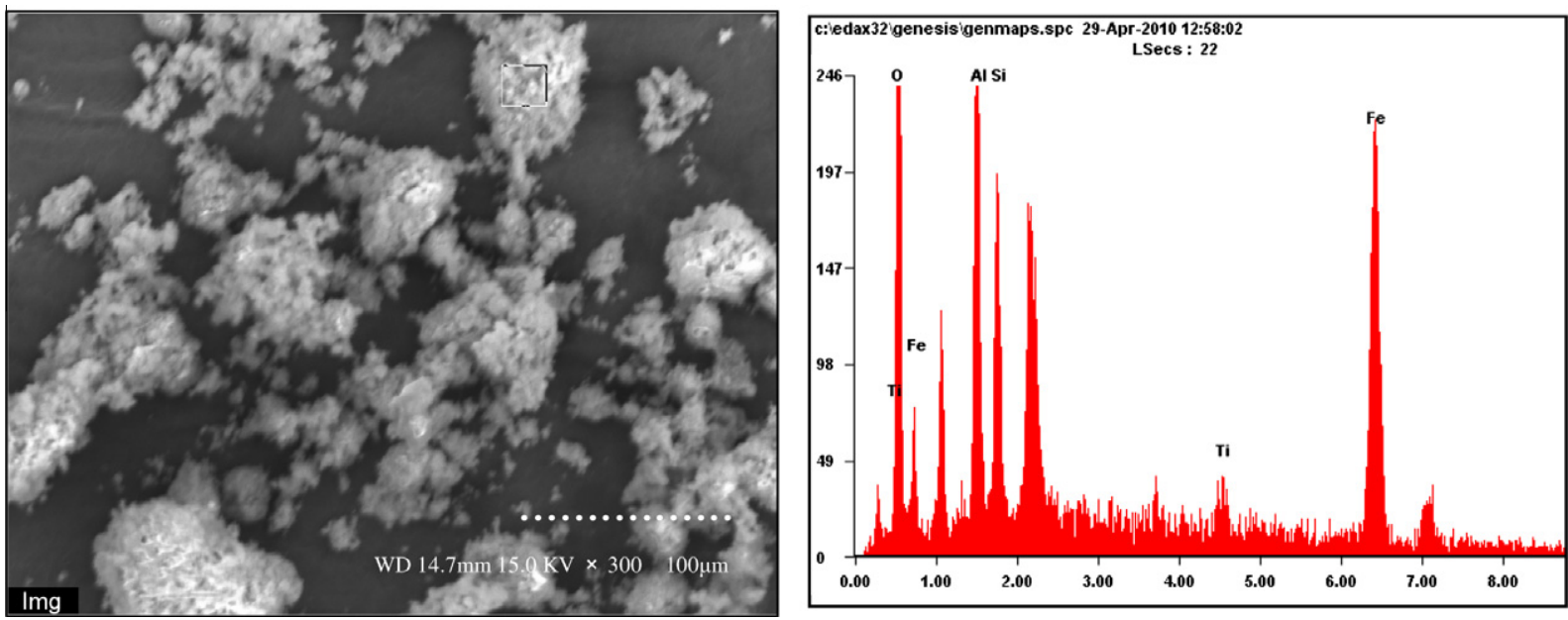

Fig. 6. Scanning electron microscope (SEM) image and fSEM-EDS analysis of RM 2\#. 


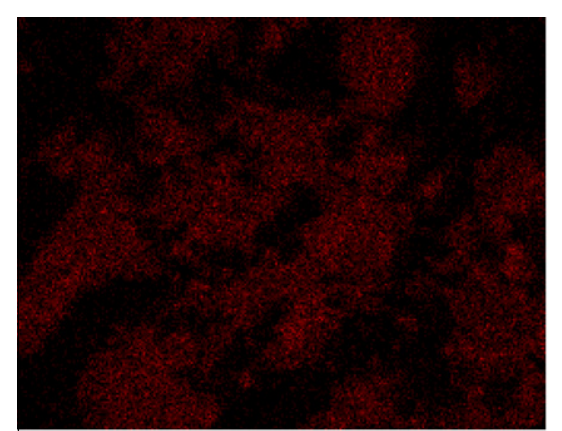

$\mathrm{Fe}$

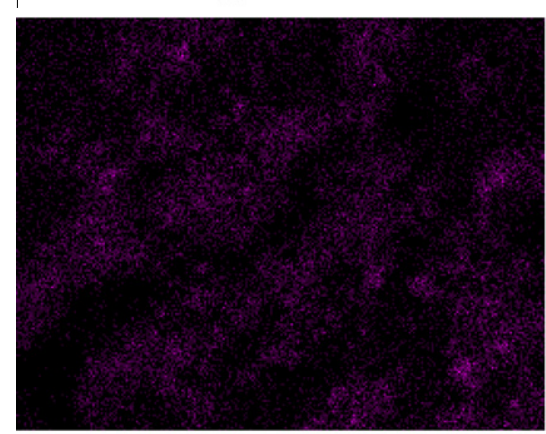

$\mathrm{Al}$

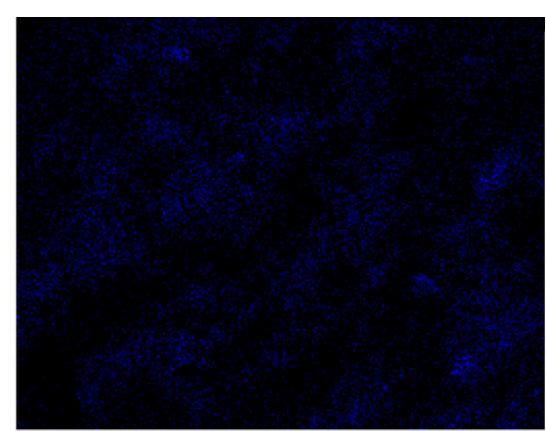

$\mathrm{Na}$

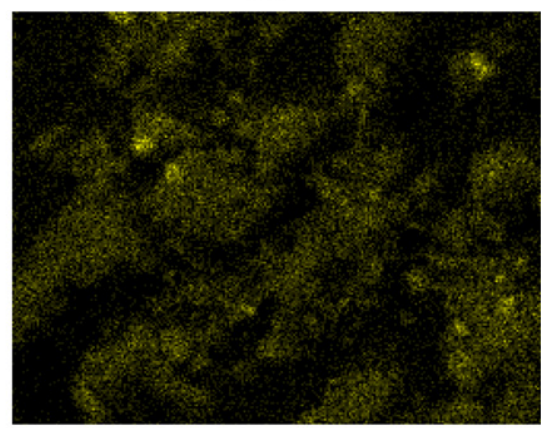

$\mathrm{Si}$

Fig. 7. Elemental (Fe $\mathrm{Na}, \mathrm{Al}, \mathrm{Si})$ dot maps of red mud.

experimental HGSMS system. For example, steal wool residues increased the uncertainty of the experiment, meanwhile, weight recovery in one stage separation was slightly low which should be considered in industrial application. More work should focus on the filling matrix, hydraulic condition, or feed-in method of HGSMS for iron mineral separation from RM.

\section{Conclusion}

The results of this study indicate that RM could be separated into high iron content part and low iron content part by HGSMS. After the separation process, high iron content part and low iron content part of RM could be recycling as resources in different industrial field. Higher magnetic intensity leads to more mount of concentrates collected and lower iron contents in the concentrates. Iron content in the residues declined when the residues were repeated fed in the HGSMS. Meanwhile, the weight of concentrates was declined compared the former separation stage and the latter one, which means the iron content in concentrates was affected by RM fed. Iron separation efficiency was limited by the deficiency of the experimental system and the improvement should be studied in the future.

\section{Acknowledgements}

Financial support provided by the National High Technology R\&D Program (863) from Ministry of Science \& Technology of China (under Grant No. 2008AA06A409-3), Public Industry Research for National Environmental Protection (under Grant No. 200709037), and the National Science and Technology Support Program of China (under Grant No. 2006BADO1B02-02) is gratefully acknowledged.

\section{References}

[1] S. Kumar, R. Kumar, A. Bandopadhyay, Resources, Conservation and Recycling 48 (2006) 301.

[2] J. Yang, B. Xiao, Construction and Building Materials 22 (2008) 2299.

[3] M. Singh, M. Garg, Construction and Building Materials 19 (2005) 25.

[4] X.B. Li, W. Xiao, G.H. Liu, Z.H. Peng, Q.S. Zhou, T.G. Qi, Transactions of Nonferrous Metals Society of China 19 (2009) 1342.

[5] D. Tuazona, G.D. Corder, Resources, Conservation and Recycling 52 (2008) 1307.

[6] C.W. Gray, S.J. Dunham, P.G. Dennis, F.J. Zhao, S.P. McGrath, Environmental Pollution 142 (2005) 530

[7] Y.R. Li, J. Wang, Z.K. Luan, Z. Liang, Journal of Hazardous Materials 177 (2010) 131.

[8] W.C. Liu, J.K. Yang, B. Xiao, Journal of Hazardous Materials 161 (2009) 474

[9] R.D. Ambashta, M. Sillanpaa, Journal of Hazardous Materials 180 (2010) 38

[10] Y. Terashima, H. Ozaki, M. Sekine, Water Research 20 (1986) 537.

[11] F. Mishima, S. Takeda, M. Fukushima, S. Nishijima, et al., Physica C 463-465 (2007) 1302.

[12] J. Svoboda, T. Fujita, Minerals Engineering 16 (2003) 785.

[13] T. Ohara, H. Kumakura, H. Wada, Physica C 357-360 (2001) 1272.

[14] A. Newns, R.D. Pascoe, Minerals Engineering 15 (2002) 465.

[15] L.Y. Li, Waste Management 21 (2001) 525. 